\title{
The Types of Tunnels Maintenance in Umbrella Arch Method
}

\author{
Arash Rostami1, Parham Kamali Dehkordi'2, Morteza Askari Ziarati1, Saman Jahani' ${ }^{3}$, \\ Kamran Lotfi ${ }^{4}$ \\ ${ }^{1}$ Department of Civil Engineering, Central Tehran Branch, Islamic Azad University, Tehran, Iran \\ ${ }^{2}$ Isfihan University, Isfihan, Iran \\ ${ }^{3}$ Department of Civil Engineering, UAE Branch, Islamic Azad University, Dubai, Dubai \\ ${ }^{4}$ Department of Civil Engineering, Zanjan Branch, Islamic Azad University, Zanjan, Iran \\ Email: Dr.Arash.Rostami@gmail.com, Kamali.d.parham@gmail.com, Morteza_Askari61@yahoo.com, \\ SamanJahani23@gmail.com, Civil.Lotfi@gmail.com
}

Received 9 January 2016; accepted 14 March 2016; published 17 March 2016

Copyright (C) 2016 by authors and Scientific Research Publishing Inc.

This work is licensed under the Creative Commons Attribution International License (CC BY).

http://creativecommons.org/licenses/by/4.0/

(c) (†) Open Access

\begin{abstract}
During tunneling in loose grounds, the ground deformation caused by drillings around the tunnel, leads to land subsidence and the adjacent tunnel which would affect tunnel structure and surrounding structures. In such situations it is necessary to improve the properties of the ground prior to drilling operations. In order to acquire tunnel face stability during excavation operations in areas with loose soil fault or areas with lack of adhesion, there are various methods such as split cross drilling, frame holder or auxiliary pre-holding methods such as umbrella arch method; preholding methods must provide safety when drilling and must be affordable, economically. In this study, we assessed the previous studies on methods and behaviors of umbrella arch strategy in reinforcing the concrete tunnels, reached the purpose with experimental and numerical methods and offered the latest design achievements, implementation progresses and analysis in relation with this method.
\end{abstract}

\section{Keywords}

Tunnel, Drilling, Umbrella Arch Method, Forepole, Arming

\section{Introduction}

Umbrella Arch Method (UAM) or Forepole is a conventional and economical method in tunnel excavation, and is in use to increase the excavation front sustainability, minimize the land subsidence, and prevent debris rocks 
falling, tunnel faces' breaking and landslides. In this strategy at first some holes will be drilled in a semi-circular pattern at a high point of the tunnel and around the tunnel crown. Putting some steel tubes into each of these holes and grouting them would form a strong umbrella arch tube above the tunnel crown. Pipes which are installed in two consecutive steps, have overlapping length and for implementation of this overlapping, a certain angle relative to the longitudinal axis of the tunnel pipe will be taken in account. The main advantages of this method can be: stress reduction in drilling front, safety increase during drilling operations, simplicity of drilling operations and as a result increase in the drilling progress speed. In fact, this method works independent of its surrounding area and leads to tension reductions [1]. Umbrella approach was first used in the early sixties in Belgium, for the construction of the subway station of Antwerp. Then this method was extensively used in America and in Japan to build tunnels with small diameters and to dig subway stations [2]. Figure 1 shows an overview of umbrella arch method.

\section{Different Methods of Umbrella Arch}

Umbrella arch methods can be divided into three categories with respect to the materials or methods which are used in reinforcing the ground:

- Eruptive injection method in sub-horizontal way (SHJG)

- Umbrella method with injecting steel pipes (ISP)

- Roof tube method

Muraki has issued some explanations for each case and method [1].

Eruptive injection in sub-horizontal method is an improved resistance technology and a way to seal the soil. Due to low performance of cement slurry injection with moderate pressures in soils with fine to medium grains, and also the existent limitations of the chemical injection methods because of high expenses and environmental risks; the high-pressure injection method is superior, considering breaks in the existing structures, allows greater penetration of slurry and also provides uniform mixing of the slurry and soil particles. Nowadays, this method is in use as an economic solution for many of the improvements and land restorations [3]. This method is applicable in a wide range of soils. Considering the fact that in sands, due to the low viscosity, less energy is in use; sands are suitable cases for injection. Sandy soils usually show acceptable behaviors [4].

Umbrella method with steel injection pipes is used, when the soil has appropriate static property or the land around the tunnel is in joined-rock type; in this method possibility of penetrating grout in the ground is low, so the grout injection only aims filling the spaces between the pipes and the pipe and the soil, in order to improve the shear resistance contact. Both injection and burst pipe methods can be used for superficial and deep tunnels. Pipe roof method is another method in pre-arming tunnels, which is done with installing large diameter steel pipes, around the drilling front. In this way, the steel pipes are placed inside the ground and then filled with grout or concrete. This method is suitable for soils with very low static properties and shallow tunnels [1].

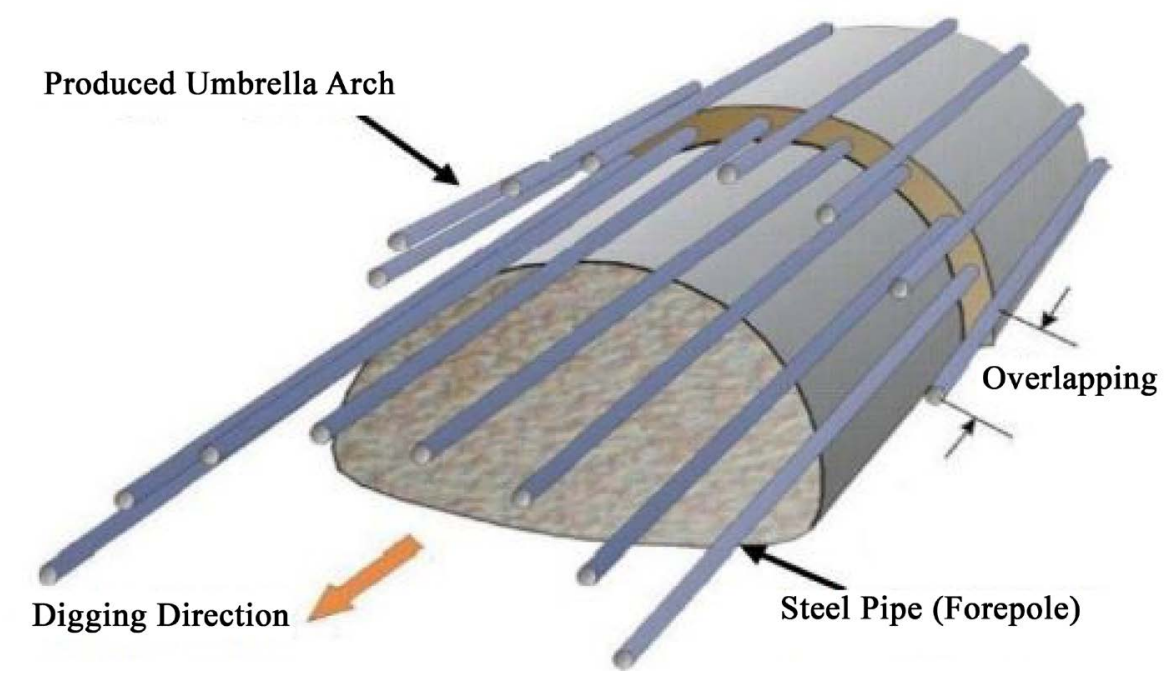

Figure 1. Overview of umbrella arch method [5]. 


\section{Mechanisms of Umbrella Arch Method}

As shown in Figure 2 during the tunnel digging, as a result of the rapid decline in normal stress and ultimately reaching the zero in drilling front, the induced stress concentration arises (point 1); so tensions over the field without tunnel maintenance reaches the zero value (between points 1 and 2). Upon installation of the holders at specified drilled intervals, vertical tensions rise again. According to Figure 2(b) it can be seen that, when the umbrella arch method is under investigation, tunnel's non-preservative section is surrounded by umbrella arch and thereby bears the burden of overhead by an umbrella vault. As there is a connection between the tunnel lining and the surrounding soil, the vertical stresses exerted on the umbrella curve are dependent on the relative stiffness between umbrella curve and the soil. It should be noted that as the deployment of an umbrella method, stress concentration reduces both in front and in back part of the drilling operations. With regard to soil particles in front of the drilling front the assumption that vertical and horizontal drillings are respectively equal to maximum main stress and minimum main stress arises $\left(\sigma_{1}\right.$ and $\left.\sigma_{3}\right)$; in Figure 2 the Mohr circle shows first stress condition when soil particles are far from digging face, and is displayed by dotes. When digging face is near to the particular soil elements, soil elements stress condition shifts from $\left(\sigma_{1}\right)$ to $\Delta \sigma_{1}$, by increasing the maximum main stress. In order to simplify the process we assumed that the minimum main stress is $\left(\sigma_{3}\right)$ and constant. Finally, as shown in Figure 2(a) when the drilling face element reaches a certain distance from soil element, the Mohr circle tangents with Mohr-Coulomb failure cop. As a result, the failure occurs in soil elements. In contrast, as shown in Figure 2(b) when umbrella method is under investigation, the maximum main stress in under control and as a result Mohr circle is not in tangent with failure and failure will not happen. Given the above, it can be concluded that the effects of the umbrella arch method on soil stress elements condition which are in face of drilling front is through limiting the increase of vertical stresses [1].

\section{Overall Reasons of Using Umbrella Method}

By examining 24 projects in which the procedure was reinforcing the tunnel face excavation by umbrella method, it was found that the main reason for the application of umbrella arch in $55 \%$ of cases is increasing the sta-

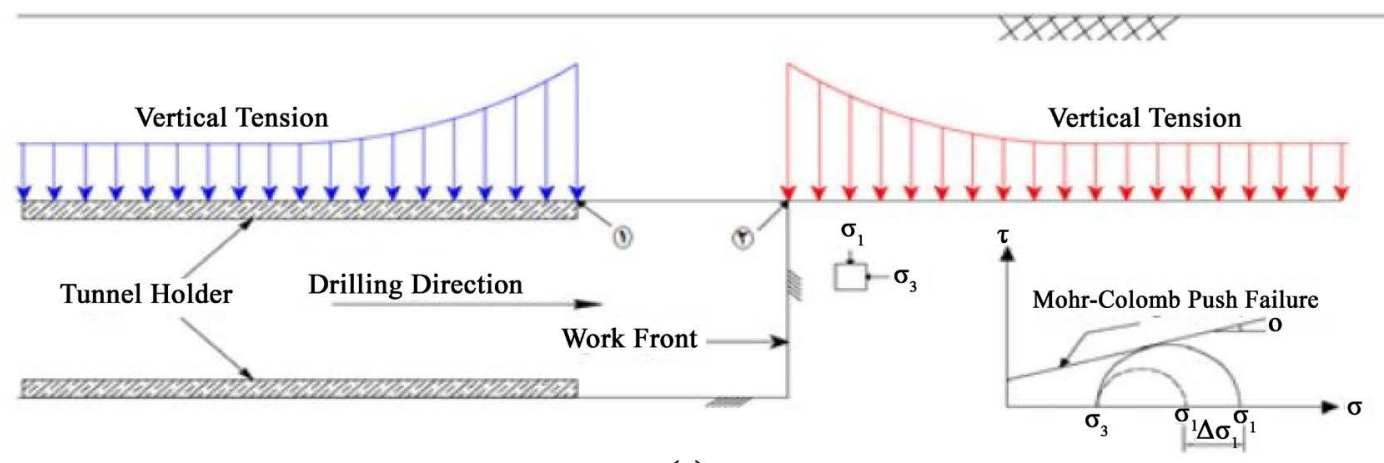

(a)

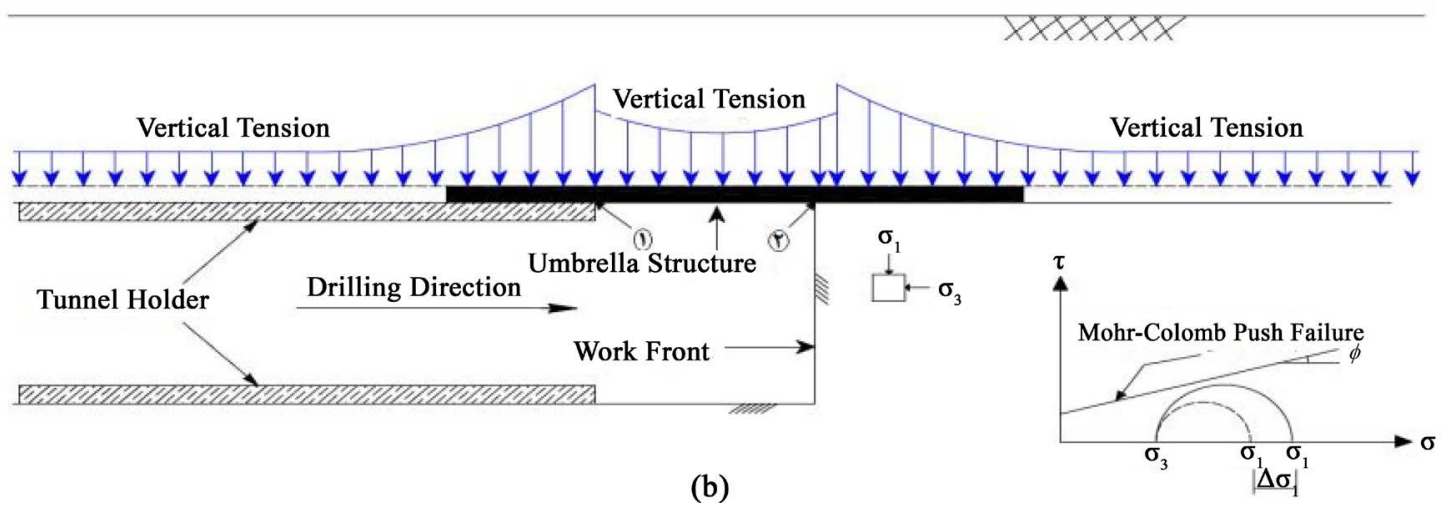

Figure 2. Vertical stress distribution along the longitudinal axis of the tunnel crown and stress on top of the drilling profile. (a) Not using the umbrella method; (b) Using the umbrella method. 
bility of the front drilling, and in 36\% of cases is lowering the land subsidence as the primary goal of using this method. Preventing roof failure or land slide in tunnel entrances consists $14 \%$ of the whole cases. Figure 3 offers the umbrella technique affects. According to the form, both SHJG method and ISP method are under usage for all three reasons, mentioned above. Considering the results of this study, the main reasons for using umbrella arch are as follows [1].

\section{Umbrella Maintenance Analysis Procedures}

In forepole behavior assessments and in analyzing the effects of them on surrounding lands, there are extensive studies conducted on both laboratory fields and numerical ways.

However, most of the designs and analysis about umbrella arch maintenance which have done in the past were on the basis of engineering experiences or the laboratory results, while the results of the numerical analysis can be very useful in optimizing the method; Figure 4 shows the numerical analysis based on the umbrella me-

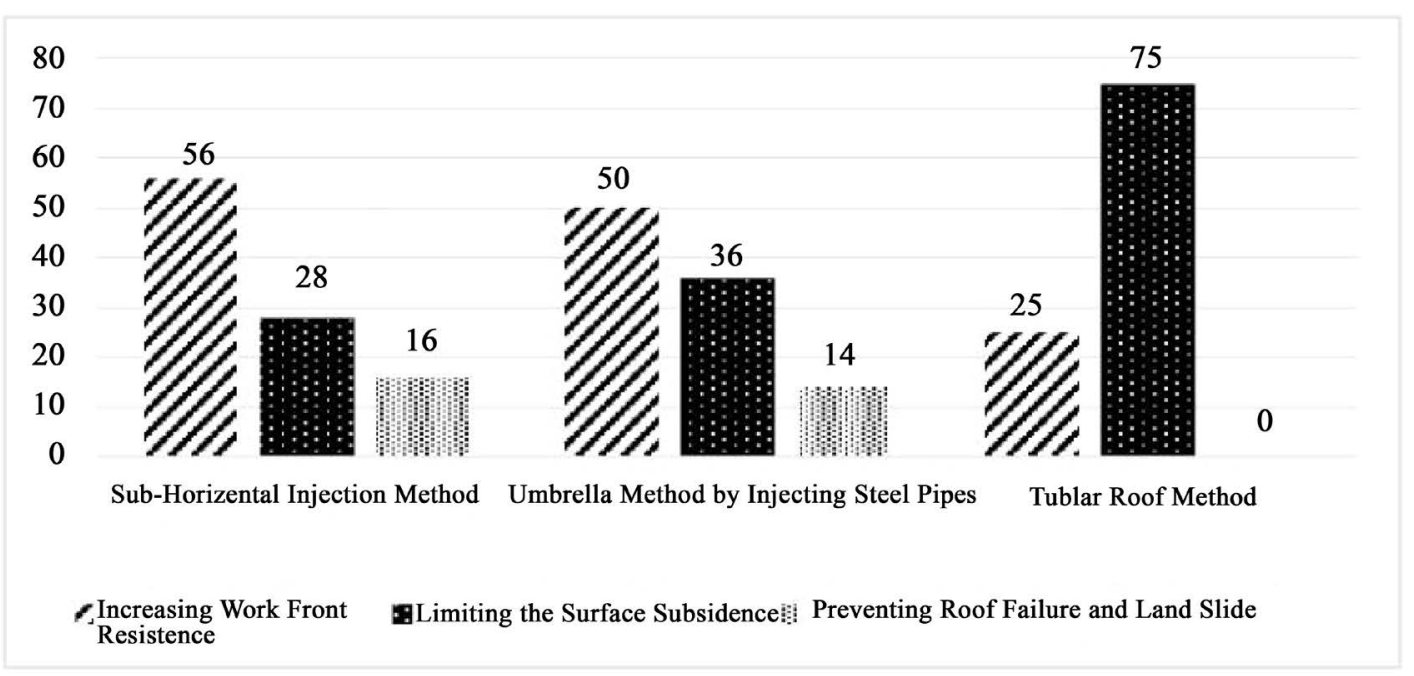

Figure 3. The effects of each of umbrella methods by separating the objects of the method [1].
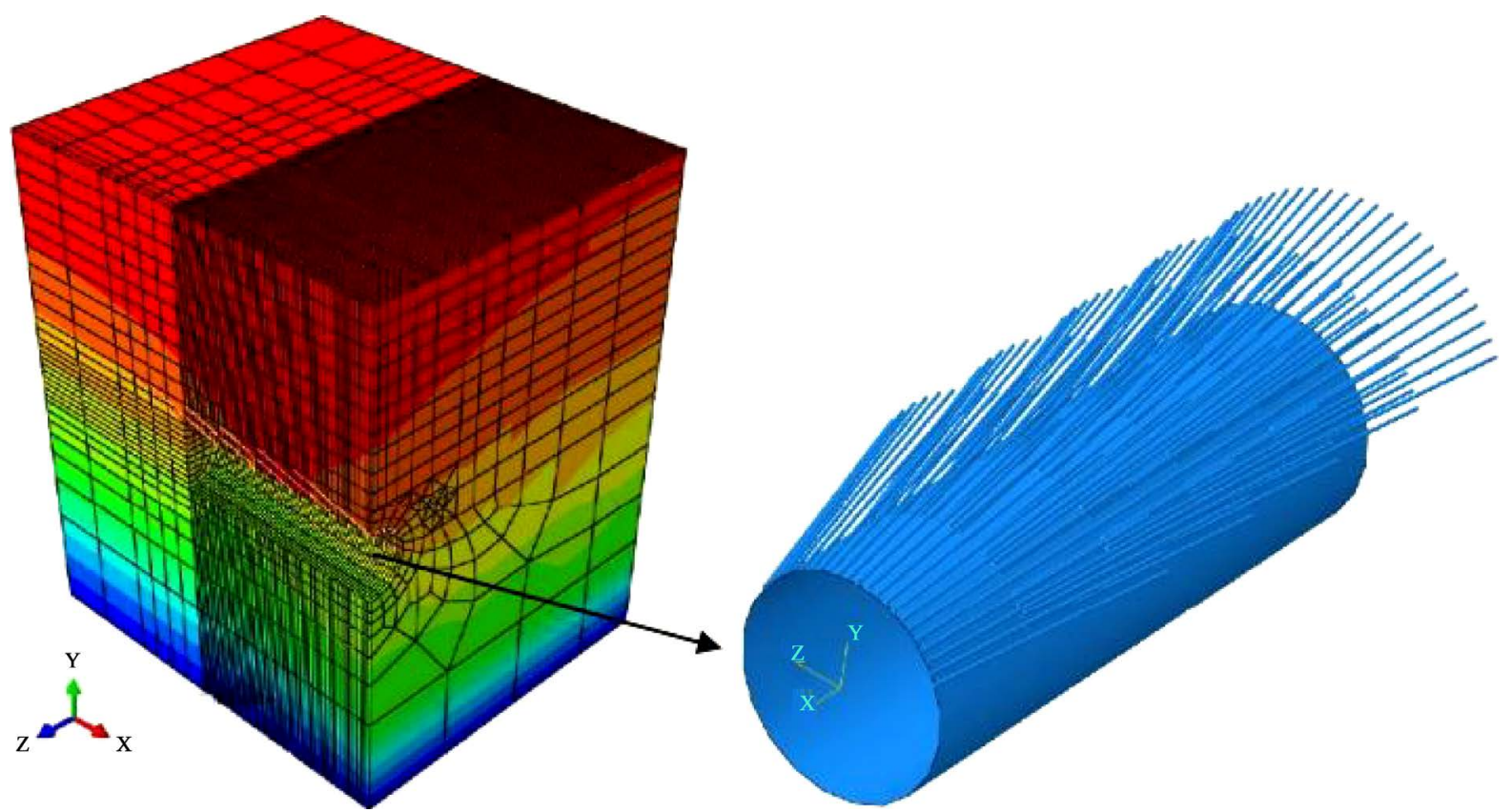

Figure 4. Numerical analysis of the tunnel maintenance method model using the umbrella arch strategy [6]. 
thod [6]. In sectional numerical analysis, constant vertical on longitudinal axis considered as the control; after modeling the drilling operations and installing support systems step-by-step, the integration of the crown and the tunnel floor has been measured.

\section{Check Out of Some of the Studies in the Field of Umbrella Arch Method}

Hisatake and Ohno [7] examined a large-scaled laboratory model to evaluate the performance of arming the above-tunnel parts and design process improvement. Their research shows that, when the forepole is used in sandy soil saturation, tunnel crown subsidence can be reduced; and the maximum subsidence of a drilled ground by arming the tunnel face through forepoles is equal to $1 / 4$ soil subsidence in similar conditions and in conditions without using reinforcing methods.

Yoo and Shin [8] did some parametric studies about the effects of forming the reinforcements in deformation behavior of tunnel face and used three-dimensional finite elements to analysis and small-scale experiments to study the soil behavior deformations; they could acquire a fine formed pipes which could optimized the ground conditions and reduce the tunnel geometry. It should be mentioned that physical modeling also had an influential role in tunnel excavation studies. In this study a wide range of conditions have been considered such as, the number, length, and stiffness of forepoles. Using the relationship between pressure and tunnel face shift and the effects of the reinforcement distribution on behavior deformation determined that the tunnel face reinforcing techniques by umbrella arch methods improves the tunnel face resistance and is useful in limiting the counter surface subsidence.

Inmuli [9] evaluated the stability of the tunnel face reinforcement with steel pipes and multistage grouting the ground due to the following factors, and did it in tunnels which are in same level with underground waters. The first factor is effective tension's affection, which can be calculated by limit theory and equilibrium theory and the other is the leakage which can be obtained using numerical analysis. This study showed that the steel pipes and multistage grouting in tunnels which are under water level have significant impacts in reducing the land subsidence. The effects of soil permeability on the exerted force on the tunnel front were conducted by finite element analysis. As a result of this research, we introduced four methods to estimate the pressure maintenance requirements, using theoretical upper limit and limit equilibrium method. As results of this study in dry conditions, using umbrella arch and grunting won't reduce the maintenance stress, significantly; but this method is able to prevent rupture of the crown at the top of the tunnel to control the displacement by doing grunting injections. It was also found that underground water greatly affects the stability of the tunnel face and under the terms of the groundwater flow in steady state, this is with respect to land subsidence, a significant proportion of holding pressures have effects on tunnel faces. By adopting the injection method, tunnel face subsidence encountered a significant reduction. Using the finite elements analysis and estimation methods, the accuracy of the resulting pressures on the supports was confirmed.

Ibrahim Ockac [10] compared the amount of subsidence in Istanbul subway with NATM method and UAM method, the results of his study showed that the amount of deformation of clay by UAM method can be controlled, effectively. He experimentally measured the maximum subsidence of tunnel crown at 8 points, and compared the maximum subsidence data in the NATM method and UAM method, the results of the investigation showed that the maintenance of the drilling front by using UAM method and NATM method at the same time is almost three times more effective than when NATM method is used alone.

Jong et al. [11] did a series of large scaled tests to evaluate the performance and effectiveness of tunnel face pipes reinforcement, in soil properties improvement and in land behavior after shifting and ground tensions during the drilling operations. According to their observations umbrella arch method arming, causes longitudinal load transfer in non-drilled area and despite making reduction in deformation, increases the stability of the tunnel face. Young also with simulating the laboratory models in numerical methods showed that the reinforcement pipes act as buried pipe beams. They transfer load longitudinally and limit area by reducing the subsidence and increasing the vertical stress and subsequent sustainability of the tunnel face.

\section{Using Inflation Tubes in Umbrella Arch Method}

Through laboratory and field experiments, Park et al. [12] studied the injected bubble volume changes in the material properties of the ground, resulting from the use of this method in highly weathered soils and rocks. The results showed that the slurry hardly penetrates the soil around the pipes and thus injection bubbles just create 
into the pipes which are in the holes. So improvement in properties around the tunnel is minimal and its effect is arising from the difficulties caused by steel pipes and concrete columns formed inside the pipes and between the pipes and holes. Therefore, it is necessary to increase the effectiveness of this approach in strengthening the stability with using more pipes (pipes which are more near together). This study introduces a new auxiliary method in reinforcing the tunnels, which is called pressure-induced inflatable pipes (PIM). In PIM method, tubes with inflation capacity would insert into the holes instead of non-inflationary tubes in UAM method. The same with UAM method, in the PIM approach the tubes have archery arrangement in the drilling face; then slurry would be injected into the pipes. The caused pressure will lead the tubes inflation. As a result, the pipes will improve soil conditions by applying pressure to the surrounding soil; in fact pipes' outside pressure would prevent deformation of the ground and will reduce the pressure on the tunnel. In PIM method three types of pipes with inflation capacity are been used which are shown in Figure 5.

1) Inflationary packer pipes with identical inflammation capacity in all respects (Figure 6(a)).

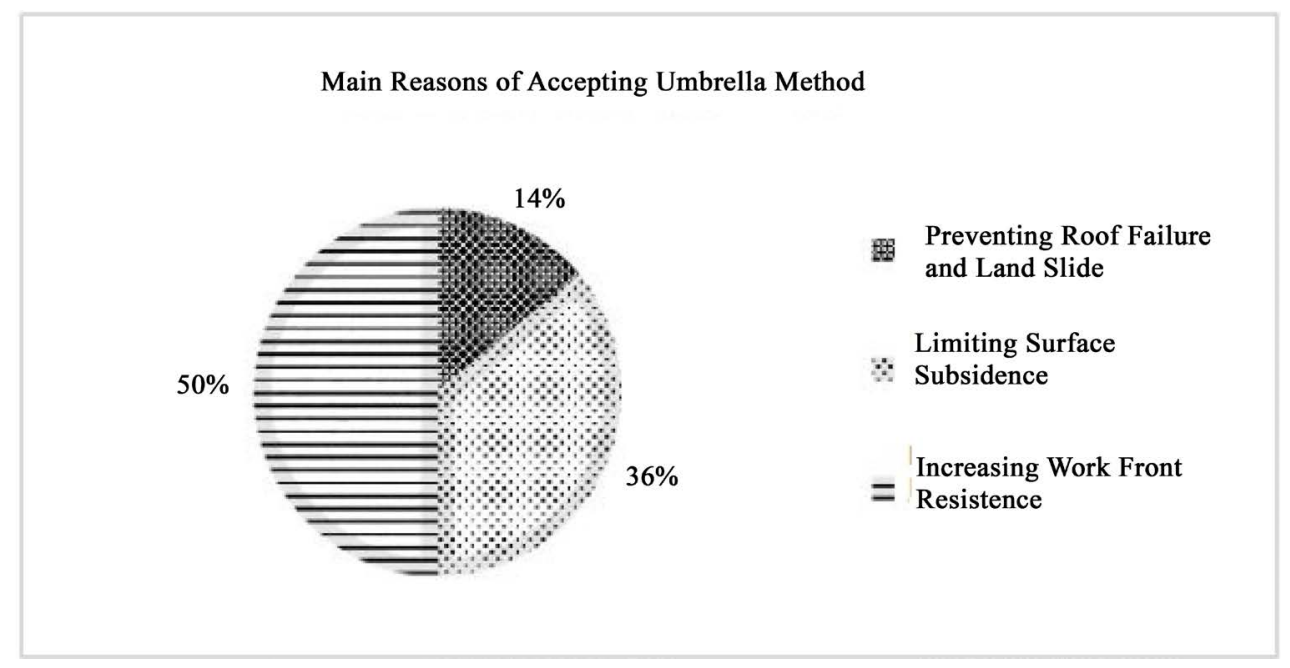

Figure 5. Main reasons for accepting umbrella method [1].

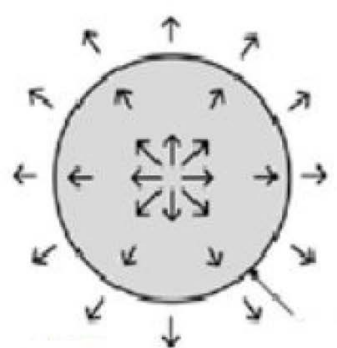

(a)

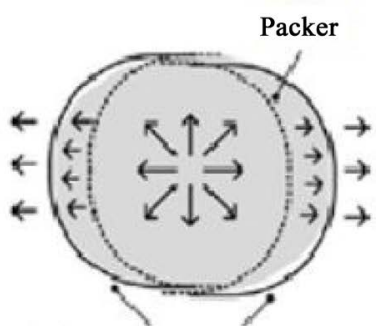

(b) Two Slices Steel Pipes

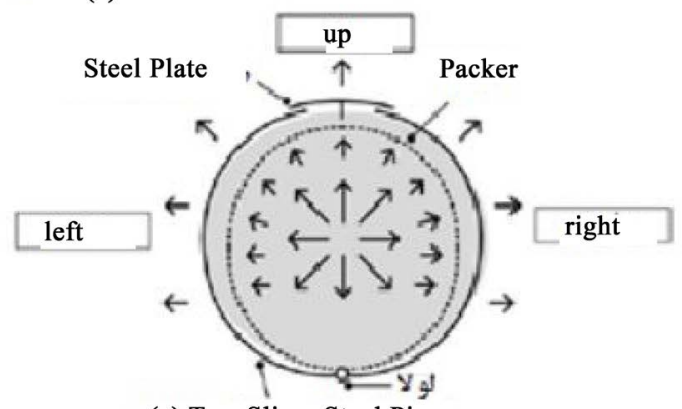

(c) Two Slices Steel Pipe

down

Figure 6. Flexible inflation pipes. 
2) Inflationary pipes which have inflammation capacity with mounting packer at two sides of the inflation steel pipes (Figure 6(b)).

3) Inflation pipes with half circular sections which are joined together by a joint at the bottom, and have inflation ability in three directions; Packer places inside the tubes, a T-shaped steel is added to the top which guides inflation in the left, right and upward (Figure 6(c)).

For validation and verification of PIM arming, laboratory model and numerical analysis model were used. The results showed that the PIM method using inflation pipes in three directions is very effective way in arming tunnels. For three inflatable tubes which are suggested in this method a chamber inflating experiments was investigated, as a result their deformation in desired directions was confirmed to use in PIM method.

\section{Results}

Studies on umbrella arch method are about the methods application and beam injection effects on reducing the shift and ground subsidence around the tunnel. In this method stabilizing of the drilling face is done by creating an umbrella structure with steel tubes, so that stress concentration would reduce in front part and back part of the tunnel face, stress level caused by drilling operations would be under control, and ultimately deformation would happen. With regards to the results of the studies, when the umbrella arc is used as a supporting structure, it can significantly reduce the land subsidence. According to the results, this pre-session support is more effective in reducing the length of the subsidence. Considering that the effective vertical stresses on umbrella holder depend on the stiffness of the holder and ground, shift in forepoles diameter will change their stiffness, which has a significant role in increasing the tunnel's stability. With increase in forepoles diameter and their number until the optimum value, the ground deformation and subsidence will reduce. With decline in reinforcements number and diameter, umbrella structures' stiffness would decrease, then surface subsidence and ground deformation rate would increase, and its impact on stability would reduce.

\section{References}

[1] Muraki, Y. (1997) The Umbrella Method in Tunnelling. Ph.D. Thesis, Massachusetts Institute of Technology, Massachusetts.

[2] Motahari, M.R. and Vafaeian, M. (2009) Finite Element Analysis of Umbrella Method in Tunneling. $4^{\text {th }}$ National Congress of Civil Engineering, Tehran, 6-8 May 2008.

[3] Hashemi, H. (2002) Use the High Pressure Injection Method for Retrofitting Soil in Tunneling Construction. $5^{\text {th }} \mathrm{Na-}$ tional Conference of Tunnel, Tehran, 7 June 2001.

[4] Atrchian. M. (2009) Use of Jet Grouting to Reduce the Settlement the Ground Surface in Vault of Tunnel. $5^{\text {th }}$ National Congress of Civil Engineering, Tehran, 4-6 May 2010.

[5] Aksoy, C.O. and Onargan, T. (2010) The Role of Umbrella Arch and Face Bolt as Deformation Preventing Support System in Preventing Building Damages. Tunnelling and Underground Space Technology, 25, 553-559. http://dx.doi.org/10.1016/j.tust.2010.03.004

[6] Kamali, P. (2015) Methods in Tunnel Maintenance. Master's Thesis, University of Isfahan, Isfahan.

[7] Hisatake, M. and Ohno, S. (2008) Effects of Pipe Roof Supports and the Excavation Method on the Displacements above a Tunnel Face. Tunnelling and Underground Space Technology, 23, 120-127. http://dx.doi.org/10.1016/j.tust.2007.02.002

[8] Yoo, C. and Shin, H.K. (2003) Deformation Behaviour of Tunnel Face Reinforced with Longitudinal Pipes-Laboratory and Numerical Investigation. Tunnelling and Underground Space Technology, 18, 303-319. http://dx.doi.org/10.1016/S0886-7798(02)00101-3

[9] Lee, I.M., Lee, I.S. and Nam, S.W. (2004) Effect of Seepage Force on Tunnel Face Stability Reinforced with MultiStep Pipe Grouting. Tunnelling and Underground Space Technology, 19, 551-565. http://dx.doi.org/10.1016/j.tust.2004.01.003

[10] Ockac, I. (2008) Control of Surface Settlements with Umbrella Arch Method in second Stage Excavations of Istanbul Metro. Tunnelling and Underground Space Technology, 23, 674-681. http://dx.doi.org/10.1016/j.tust.2007.12.005

[11] Jong, H.S., Yong, K.C., Oh, Y.K. and Sang, D.L. (2008) Model Testing for Pipe-Reinforced Tunnel Heading in A Granular Soil. Tunnelling and Underground Space Technology, 23, 241-250. http://dx.doi.org/10.1016/j.tust.2007.04.012

[12] Park, J.J., Cho, I.S. and Lee, S.W. (2012) Tunnel Reinforcement by Using Pressure-Induced Inflatable Pipes Method. Geotechnical and Geoenvironmental Engineering, 138, 1483-1491. http://dx.doi.org/10.1061/(ASCE)GT.1943-5606.0000725 